\title{
A qualitative analysis of the adhrence between the Information Tecnology Solution Aquisition Guide, for Brazilian Federal Public Administration and, the CMMI models
}

\author{
Luiz S.P. Silva, Alexandre \\ M.L Vasconcelos Federal \\ University of Pernambuco \\ (UFPE) \\ Recife - PE - Brazil \\ 1sps@cin.ufpe.br, \\ amlv@cin.ufpe.br
}

\author{
Renata T. Moreira \\ Federal University of Lavras \\ (UFLA) \\ Lavras - MG - Brazil \\ renata@dcc.ufla.br
}

\author{
Maurício R. A. \\ Souza \\ Federal University \\ of Minas Gerais \\ Belo Horizonte - \\ MG - Brazil \\ mrasouza@dcc.ufmg.br
}

\author{
Suzana C. B. Sampaio \\ University Federal Rural of \\ Pernambuco (UFRPE) \\ Recife - PE - Brazil \\ suzana@deinfo.ufrpe.br
}

Abstract - quality models and standards guide Software Process Improvement Initiatives. Usually aiming to establish the best practices to instruct the definition of processes and support organizational assessment of the maturity and capability level. However, despite these initiatives, the best practices application in Brazilian public organizations is impaired by various obstacles regarding the process of Contracting IT solutions by the Federal Public Administration (APF), the main contractor of software and services in Brazil. Among these obstacles the ones that stand out are process complexity and the continuous supervision of control bodies. In order to minimize these obstacles, the court Union Accounts (TCU), recommended the establishment of the Normative Instruction SLTI/MPOG 04/2014, containing guidelines for the acquirement of IT Solutions and a Guide for Contracting IT Solutions (GCSTI). This work aims at identifying the maturity and adherence of GCSTI relative to CMMI models. To achieve this goal, defined and carried out a method of mapping between GCSTI and CMMI models. The survey results show the maturity and adherence to CMMI models based on procedures defined in GCSTI.

Keywords: Software and Services Process Improvement, Process IT Solutions Contracting, CMMI models.

\section{INTRODUCTION}

The advances and increasing dependence of Information Technology Services (IT) (which include care services, information storage, data, customer support and the various resources and technological means available to society) caused service providers to struggle at maintaining the expected service quality required by clients (LIRA et al, 2008; BRICKLEY, 2001; BERGAMASCHI, 2004. Researchers and practioners investigate the factors that affect the provision of IT services to meet the needs and expectations of customers (CRUZ et al., 2011, SILVA, 2013).

The Brazilian Federal Public Administration (APF) is the largest consumer and buyer of IT products and services in Brazil (SILVA, 2013). Its procurement process for contracting IT services and solutions is guided by the Normative instructions IN / SLTI / MPOG 04/2014 and the Guide on Contracting IT Solutions - the GCSTI. However, from the providers perspective, meeting these recommendations is complex, and may incur in additional expenditure for achieving compliance.
Therefore, this study aims to evaluate the process of Contracting IT solutions based on CMMI models, in order to analyze what is the maturity required for execution of the APF procurement process. We mapped the GCSTI recommendations to the good practices provided by the CMMI models "CMMI for development" (CMMI-DEV), CMMI for Service (CMMI-SVC), and CMMI for Acquisition (CMMI-ACQ).

This paper is organized as follows: Section I presents the theoretical framework; Section II presents the mapping between the GCSTI and CMMI models, Section III the challenges founds, and Section VI, presents conclusions the Work Completion.

\section{I . THEORETICAL FRAMEWORK}

The normative instruction IN/SLTI/MPOG 04/2014 (SLTI, 2015) provides governance mechanisms for contracting IT services and solutions. To support the compliance to the IN/SLTI/MPOG 04/2014, the Good Practices Guide on Contracting IT Solutions (GCSTI) was created as a compilation of process, activities and tasks executed during the procurement process (CAVALCANTI, 2015). It is composed of three phases: (i) IT Solution Acquisition Plan; (ii) Selection of IT Solution Provider; and (iii) IT Solution Contract Management.

The CMMI Model (Capability Maturity Model Integration) is a collection of components from several maturity models and an assessment process maintained by the CMMI Institute (GALLAGHER et al., 2010; CHRISSIS et al., 2010; FORRESTER et al., 2010). These components are grouped in constellations, each one providing guidelines for process improvement in a given area of interest, such as acquisition (ACQ), development (DEV) and services (SVC).

\section{MAPPING BETWEen THE GUIDE OF IT SOLUTIONS CONTRACTING AND MODELS CMMI}

In order to provide an assessment of the required organization maturity for providing IT services and solutions in compliance with the GCSTI, we mapped the GCSTI recommendations to the CMMI practices. The mapping was executed in nine steps: (i) Study the models; (ii) Delimitation of the work scope; (iii) Definition of the classification criteria; (iv) Establishment of initial Mapping Form; (v) Establishment of the Standard Form for Mapping; (vi) Establishment of the Analysis Standard Form; (vii) Comparing Models; (viii) Consolidation of Results; and (ix) Validation with the Peer Review Technical.

We evaluated the compliance of the GCSTI processes to Specific Practices from the CMMI models. Due to space restriction, 
Table 1 provides only a summary of the mapping. For each phase of the GCSTI process (IT Solution Acquisition Plan, Selection of IT Solution Provider, and IT Solution Contract Management) we evaluated the compliance with the Specific Practices from each of the CMMI Models (DEV, SVC and ACQ) Practice Areas.

Some important aspects were identified in the final consolidation of the results of the mapping between MCTI model and CMMI models. The core Process Areas (common to the three models) had the same percentage of attendance by GCSTI model processes

Table 1. Mapping Consolidation

\begin{tabular}{|c|c|c|c|}
\hline $\begin{array}{l}\text { Process } \\
\text { Areas }\end{array}$ & $\begin{array}{c}\text { CMMI } \\
\text { ACQ }\end{array}$ & $\begin{array}{l}\text { CMMI } \\
\text { DEV }\end{array}$ & $\begin{array}{l}\text { CMMI } \\
\text { SVC }\end{array}$ \\
\hline PP & $100 \%$ & $100 \%$ & \\
\hline WP & & & $100 \%$ \\
\hline PMC & $100 \%$ & $100 \%$ & \\
\hline WMC & & & $100 \%$ \\
\hline $\mathrm{CM}$ & $85,71 \%$ & $85,71 \%$ & $85,71 \%$ \\
\hline PPQA & $100 \%$ & $100 \%$ & $100 \%$ \\
\hline MA & $68,75 \%$ & $68,75 /$ & $68,75 /$ \\
\hline SAM & & $100 \%$ & $100 \%$ \\
\hline REQM & $80 \%$ & $80 \%$ & $80 \%$ \\
\hline SD & & & $100 \%$ \\
\hline$\overline{\mathrm{OPF}}$ & $11,11 \%$ & $11,11 \%$ & $11,11 \%$ \\
\hline OPD & $50 \%$ & $50 \%$ & $50 \%$ \\
\hline DAR & $100 \%$ & $100 \%$ & $100 \%$ \\
\hline OT & $28,57 \%$ & $28,57 \%$ & 28,57 \\
\hline IPM & $70 \%$ & $70 \%$ & \\
\hline IWM & & & $70 \%$ \\
\hline RSKM & $85,71 \%$ & $85,71 \%$ & $85,71 \%$ \\
\hline ARD & $100 \%$ & & \\
\hline AM & $100 \%$ & & \\
\hline AVER & $87,50 \%$ & & \\
\hline AVAL & $100 \%$ & & \\
\hline SSAD & $100 \%$ & & \\
\hline ATM & $100 \%$ & & \\
\hline $\mathrm{RD}$ & & $100 \%$ & \\
\hline $\mathrm{TS}$ & & $100 \%$ & \\
\hline PI & & $100 \%$ & \\
\hline VER & & 87,50 & \\
\hline VAL & & $100 \%$ & \\
\hline CAM & & & $16,67 \%$ \\
\hline IRP & & & $50 \%$ \\
\hline SSD & & & $91,67 \%$ \\
\hline SCON & & & $75 \%$ \\
\hline SST & & & $60 \%$ \\
\hline STSM & & & $50 \%$ \\
\hline
\end{tabular}

Based on these results, it is noted that there is a deficiency in the sequence of execution of GCSTI model processes with respect to CMMI models. Whereas the GCSTI model serves various process areas of CMMI models in different maturity levels. While that process areas related to engineering Acquisition, Development and Services are attended by almost $100 \%$ (Maturity Level 3 ), the process areas from Maturity Level 2, which defines the "managed level", is not attended completely. Therefore, the areas related to level 3 maturity, are not being performed after the meeting the level 2 process areas maturity, which can result in problems and difficulties in implementing the processes.

The mapping between CMMI Models and GCSTI process showed that, although it has a high adherence to CMMI Process Areas, the GSCTI process does not provide a sequential or staged implementation suggestion. Thus some practices from CMMI
Maturity Level 2 are not completed attended, and it may lead to difficulty in introducing practices from higher maturity levels.

\section{CONCLUSIONS}

The results shows that there is a lack of alignment between the GCSTI process and the methodologies, norms and models commonly applied as quality standards in the software and service industry. The CSGTI defines process and activities equivalent to CMMI Maturity Level 3. In this Maturity Level, organizations already have processes defined for managing projects, services and acquisition. Therefore, there is a challenge in elevating the maturity of IT organizations in Brazil, promoting their capacity in order to become ready for providing solutions for the government. By achieving this, the brazilian government will promote small companies, empowering the software industry and ensuring constitutional principles on the IT contracts.

\section{REFERENCES}

ABES - Brazilian Association of Software Companies. 2015. Available at: $<\mathrm{http}: / /$ www.abes.org.br/>. Accessed: 08/02/2016.

ABREU, M. F. The risks of IT outsourcing and the adoption of new IT and its relations with the risks to the competitive strategies of organizations. 2009.

BERGAMASCHI, Sydney. Models for the Management of Outsourcing Information Technology: An Exploratory Study. Thesis (doctoral) - University of São Paulo, 2004.

Bernstorff, V. H; CUNHA, J. C. O. organizations to seek and achieve with the outsourcing of information technology In: XXIII Annual Meeting of ANPAD 1999, Foz do Iguaçu / PR ANAL. ANPAD 1999.

BRAGA, R. Audit of IT Governance. Brasília: TCU / ISC 2009.

CAVALCANTI, S.C. The New Model IT Solutions Contracting for the Federal Public Administration. 2a. Ed. Belo Horizonte. Publishing Forum 2015.

CHRISSIS, M.D., KONRAD, M. AND S. SHRUM "CMMI:

guidelines for process integration and product improvement. " Addison-Wesley. 2010.

CRUZ, C. S. of. IT Governance and Legal Compliance in the Public Sector: A Framework Reference Normative for IT Service Contracts. 2008. Master's Thesis. Catholic University of Brasilia, Brasilia, 2008.

Available at:

$<$ Http://www.bdtd.ucb.br/tede/tde_arquivos/3/TDE-2008-1125T123713Z-687 / Public / TextoCompleto Cruz - 2008.pdf>.

Accessed: 15/12/2016.

FORRESTER, E., Buteau, B., Shrum, S. CMMI: Guidelines exceeds Service. Addison-Wesley. 2010.

GALLAGHER, B., PHILliPS, M., RICHTER, K., Shrum, S.

CMMI: Guidelines for Improving the Acquisition of Products and Services. Addison-Wesley. 2010.

ISO / IEC, 2011. International Organization For Standardization / International Electrotechnical Commission. ISO / IEC 20000 Information technology- Management Service, Geneve: ISO 2011. LIRA, W. S .; CANDID, G. A .; ARAUJO, G. \& M. BARROS, M. A. The search and the use of information in organizations. Perspectives on Information Science. Vol. 13, no. 1, Belo Horizonte, 2008.

SEI, 2010. Software Engineering Institute. CMMI for Development. 2010.

SILVA, L. S. P. Model of IT Solutions Contracting: A Comparative Analysis to Identify the maturity and adherence to CMMI-ACQ models, CMMI-DEV and CMMI-SVC. 2013.

Dissertation (Master in Computer Science) - Computer Center Federal University of Pernambuco, Recife, Pernambuco, 2013. 